\title{
The effect of physical activity on cognition relative to APOE genotype (PAAD-2): study protocol for a phase II randomized control trial
}

Kyoung Shin Park', Alexis B. Ganesh', Nathaniel T. Berry², Yashonda P. Mobley ${ }^{1}$, William B. Karper ${ }^{1}$, Jeffrey D. Labban', Christopher N. Wahlheim³ ${ }^{3}$ Tomika M. Williams ${ }^{4}$, Laurie Wideman ${ }^{1}$ and Jennifer L. Etnier ${ }^{1 *}$

\begin{abstract}
Background: By 2050, the prevalence of Alzheimer's disease (AD) in the United States is predicted to reach 13.8 million. Despite worldwide research efforts, a cure for AD has not been identified. Thus, it is critical to identify preventive strategies that can reduce the risk of or delay the onset of AD. Physical activity (PA) has potential in this regard. This randomized clinical trial aims to (a) test the causal relationship between PA and AD-associated cognitive function for persons with a family history of $\mathrm{AD}(\mathrm{FH}+)$, (b) determine the moderating role of apolipoprotein epsilon 4 (APOE4) carrier status on cognition, and (c) assess cerebral structure, cerebral function, and putative biomarkers as mediators of the effects of PA on cognition.
\end{abstract}

Methods: We are recruiting cognitively normal, middle aged (40-65 years) sedentary adults with $\mathrm{FH}+$. Participants are randomly assigned to a 12-month PA intervention for 3 days/week or to a control group maintaining their normal lifestyle. Saliva samples are taken at pre-test to determine APOE genotype. At pre-, mid-, and post-tests, participants complete a series of cognitive tests to assess information-processing speed, verbal and visual episodic memory, constructional praxis, mnemonic discrimination, and higher-order executive functions. At pre- and post-tests, brain imaging and blood biomarkers are assessed.

Discussion: We hypothesize that 1) the PA group will demonstrate improved cognition compared with controls; 2) PA-derived cognitive changes will be moderated by APOE4 status; and 3) PA-induced changes in neural and blood biomarkers will contribute to cognitive changes and differ as a function of APOE4 status. Our results may provide important insights into the potential of PA to preserve neurocognitive function in people with a heightened risk of AD due to $\mathrm{FH}+$ and as moderated by APOE4 status. By using sophisticated analytic techniques to assesS APOE as a moderator and neurobiological mechanisms as mediators across trajectories of cognitive change in response to PA, we will advance our understanding of the potential of PA in protecting against AD.

Trial registration: ClinicalTrials.gov NCT03876314. Registered March 15, 2019.

Keywords: Alzheimer's disease, Apolipoprotein, BDNF, Dementia, Episodic memory, Executive function, Fluid intelligence, Exercise intervention, MRI

\footnotetext{
* Correspondence: jletnier@uncg.edu

'Department of Kinesiology, University of North Carolina at Greensboro, Greensboro, NC 27402, USA

Full list of author information is available at the end of the article
}

(c) The Author(s). 2020 Open Access This article is licensed under a Creative Commons Attribution 4.0 International License, which permits use, sharing, adaptation, distribution and reproduction in any medium or format, as long as you give appropriate credit to the original author(s) and the source, provide a link to the Creative Commons licence, and indicate if changes were made. The images or other third party material in this article are included in the article's Creative Commons. licence, unless indicated otherwise in a credit line to the material. If material is not included in the article's Creative Commons licence and your intended use is not permitted by statutory regulation or exceeds the permitted use, you will need to obtain permission directly from the copyright holder. To view a copy of this licence, visit http://creativecommons.org/licenses/by/4.0/ The Creative Commons Public Domain Dedication waiver (http://creativecommons.org/publicdomain/zero/1.0/) applies to the data made available in this article, unless otherwise stated in a credit line to the data. 


\section{Background}

\section{Background and rationale}

Dementia is a general term describing a group of symptoms associated with memory decline and other cognitive impairments severe enough to disturb a person's ability to perform daily activities. Alzheimer's disease (AD) is the most common form of dementia (approximately 60-80\%) and is a progressive, neurodegenerative ailment [1]. The global prevalence of AD is expected to reach 152 million by the year 2050 and the global costs of dementia equated to $\$ 1$ trillion in 2019 , and these costs are predicted to reach $\$ 2$ trillion by 2030 [2]. Although scientists are exploring disease-modifying pharmacological interventions [3], there is currently no known cure for $\operatorname{AD}[4,5]$. Therefore, researchers are also focusing on interventions with the potential to delay the onset of the disease by targeting modifiable risk factors [6]. Delaying the onset of AD by 1 year could reduce its incidence by 11\% [7] and delaying the onset by 5 years could reduce the number of Americans with AD by $29-43 \%$ and total health care costs by $\$ 83$ - \$367 billion [1].

\section{The potential of physical activity}

About one-third of $\mathrm{AD}$ cases worldwide are related to modifiable risk factors, with the largest proportion of cases in the United States attributable to a lack of physical activity (PA) [5]. Retrospective [8, 9] and prospective [10-13] studies have shown that greater PA predicts better cognitive performance and a decreased risk of dementia. Meta-analytic reviews of this literature have reported promising benefits of PA specifically for the prevention of $\mathrm{AD}(\mathrm{OR}=0.14-0.72)$ [10, 14-17]. Furthermore, experimental studies have shown that increasing PA results in improved cognitive performance in cognitively normal adults [18-21], people with mild cognitive impairment (MCI) [22], and persons with self-reported memory complaints [23]. Meta-analytic reviews have reported a moderate degree of beneficial effects of PA on cognitive function in cognitively normal older adults [24-27]. Therefore, it is important to further our understanding of how PA might be used to prevent or delay AD.

Individuals with a family history of $\mathrm{AD}(\mathrm{FH}+)$ and who are carriers of the apolipoprotein epsilon 4 allele (APOE4+) have a 46-61\% heightened risk of $\mathrm{AD}$, making them an important target for prevention [28]. Importantly, APOE4 contributes independently to the risk of AD, above and beyond FH [28-30]. Cross-sectional and prospective studies have shown that the relationship between PA and cognition is moderated by APOE4 such that larger cognitive benefits are typically [31-34], but not always [35, 36], reported for $A P O E 4+$ as compared to APOE4 non-carriers (APOE4-). In cognitively normal older women with a $\mathrm{FH}+$, the relationship between aerobic fitness and cognitive performance was more positive for APOE4+ than for APOE4- [37]. However, recently it was reported that participation in an 8-month PA program improved cognition in individuals with a $\mathrm{FH}+$ irrespective of APOE4 carrier status [38]. To date, there is a critical gap in the literature because there is no evidence from randomized control trials (RCTs) regarding the extent to which PA affects cognition in cognitively normal, middle-aged, $\mathrm{FH}+$ individuals relative to $A P O E 4$ carrier status.

\section{Lack of comprehensive neurocognitive assessment}

The extant literature also lacks a comprehensive assessment of AD-sensitive cognitive changes in response to PA. Every area of cognitive function is distinctively affected by $\mathrm{AD}$ [39] and thus needs to be appraised in terms of its responsiveness to PA. Well-established patterns of cognitive deterioration in $\mathrm{AD}$ appear in verbal and visual episodic memory, auditory and visuospatial information processing, visuospatial constructional praxis, attention, and executive functions (EFs) including working memory, set-shifting, inhibitory control, planning, and fluid intelligence [39]. RCTs on the benefits of PA interventions for cognition in people with a heightened risk for $\mathrm{AD}$ (i.e., $\mathrm{MCI}$ ) have focused on measures of general cognition [23], a subset of the domains of EF [22] or memory $[40,41]$. The use of these limited measures impedes our ability to determine how specific aspects of cognitive function differentially respond to PA [23]. Therefore, a comprehensive assessment is needed to fully determine the effects of PA on various aspects of cognition for individuals with a heightened risk of AD.

In addition to assessing behavioral measures of cognition, we will also assess changes in blood biomarkers and brain health in individuals with $\mathrm{FH}+$ relative to their APOE4 status and the PA intervention. With regard to blood biomarkers, we are focused on putative biological markers sensitive to effects of PA and/or that have implications for AD. Brain-derived neurotrophic factor (BDNF) is important for neuronal survival, growth, and maintenance [42] and has been implicated in the consolidation of memory [43-45]. Peripheral levels of BDNF decrease during $\mathrm{AD}$, and higher BDNF is associated with slower decline in AD [46]. Although evidence is inconsistent, chronic PA increases peripheral BDNF [22, 47, 48] and exercise-induced changes in peripheral BDNF are associated with hippocampal volume changes [21]. This evidence supports BDNF as a potential mechanism which could mediate the benefits of PA for cognition. In this study, BDNF is of primary interest, but we assess additional biomarkers implicated in the relationship between PA and AD (see Table 1 for the summary of rationale supporting the inclusion of each biomarker). Changes in biological markers in response to PA will also be examined relative to APOE4 carrier status. 
Using magnetic resonance imaging (MRI), we will also assess brain structure volume, task-evoked brain activity, functional connectivity, white matter microstructure, and white matter hyperintensities as measures of brain health. Non-experimental studies have shown that greater aerobic fitness is associated with greater hippocampal volume [70-72] and less age-related neural degeneration, particularly in the prefrontal, superior parietal, and temporal cortices [73]. Baseline PA is predictive of hippocampal volume 9 years later [74] and aerobic fitness is associated with less age-related dysfunction in functional connectivity [75]. In RCTs, PA interventions have resulted in increased grey matter in the prefrontal cortex [76], hippocampal volume [21], resting cerebral blood flow [77], task-evoked activity [78], white matter integrity [79], and functional connectivity in cognitively-relevant regions $[80,81]$.

Brain health differs by APOE4 status in cognitively normal adults, evidenced by right hippocampal atrophy [82, 83], decreased cortical thickness [84, 85], and reduced grey matter $[86,87]$ in $A P O E 4+$ compared to APOE4- individuals. White matter deficits, including decreased diffusion anisotropy [88-91], have also been found in $A P O E 4+$, with the lowest fractional anisotropy in individuals who are $\mathrm{FH}+$ and $A P O E 4+$ [92]. Further, differences in functional connectivity as a function of APOE4 status have been shown in young [93], middleaged, and older adults [94, 95]. However, to date, few studies have reported the moderating effects of $A P O E$ on the relationship between PA and brain health, and results have been inconsistent. In one study, PA was found to be associated with greater memory-related brain activation, with the strongest associations in people with APOE4+ [96]; however, another study found a positive association between PA and hippocampal volume that was not moderated by APOE4 status [97]. To our knowledge, there is no evidence from RCTs regarding the effects of a PA intervention on brain health relative to APOE4. In this study, we will assess changes in brain health in response to a PA program and explore the moderating role of $A P O E 4$ carrier status.

\section{Study objectives}

This protocol describes the design and methods of a RCT aiming to 1) test the causal link between PA and cognitive performance in persons with a $\mathrm{FH}+$, 2) determine if the effect of PA on cognitive performance is moderated by APOE4 carrier status, 3) assess the extent to which measures of brain health and putative biomarkers serve as mediators of the effects of PA on cognition and 4) determine the extent to which these mediated relationships are moderated by APOE4 carrier status. Our results might provide important insights into the potential of PA to foster cognitive performance in those with a heightened familial and genetic risk of AD. Given that midlife PA has been shown to reduce the risk of $\mathrm{AD}[98,99]$, beneficial responses to PA could delay $\mathrm{AD}$ in this particularly susceptible population, and thereby meaningfully reduce the prevalence of AD [6].

\section{Methods and design}

Study design and setting

In this RCT, middle-aged sedentary adults with a $\mathrm{FH}+$ are pre-tested (baseline), randomly assigned to a 12-month PA intervention or a usual-care control, mid-tested (6 months after baseline), and post-tested (12 months after baseline). The study sites are laboratories at the Department of Kinesiology and the Gateway MRI Center at the University of North Carolina at Greensboro located in Greensboro, North Carolina, USA, along with local YMCAs where the PA intervention is provided. This study was approved by the university's Office of Research Integrity and this protocol is reported in accordance with the

Table 1 Biomarkers to be measured and potential mechanisms

\begin{tabular}{ll}
\hline Biomarker & Potential mechanism or proposed pathway \\
\hline BDNF & Crucial role in plasticity of central and peripheral nervous systems [49]; Exercise responsive [50, 51]; Binds \\
& to tropomyosin-related kinase B (TrkB) receptor, $\uparrow$ glucose uptake, interacts with autonomic nervous system [42] \\
SAP & Biomarker of progression to AD [52,53] \\
Albumin & Neuroprotective due in part to anti-oxidative properties [53, 54] \\
Glucose & Levels altered by exercise and related to irisin and/or BDNF; high levels have negative effect on neuroplasticity \\
& {$[55,56]$} \\
IGF-I & Interacts with BDNF in response to exercise; neural plasticity [57-59] \\
APOE & Linked to A clearance and lipid homeostasis [53, 60] \\
alpha-2 macroglobulin & Proteinase inhibitor associated with AD disease severity [53, 61] \\
Insulin & Altered by exercise and irisin; $\uparrow$ insulin sensitivity [62, 63] \\
Irisin & Exercise $\uparrow$ FNDC5/irisin release from muscle; $\uparrow$ BDNF transcription in hippocampus [42, 64, 65] \\
TNF-a & Pro-inflammatory [66, 67]; related to dementia [68, 69]
\end{tabular}

$A D$ Alzheimer's disease, $A P O E$ apolipoprotein epsilon 4 allele, BDNF Brain-derived neurotrophic factor, CRP C-reactive protein, FNDC5 fibronectin type III domain containing 5, IGF insulin-like growth factor, IL interleukin, SAP serum amyloid P, TNF Tumor necrosis factor 
SPIRIT guidelines [100]. See the SPIRIT checklist in additional file 1 for more information.

\section{Participants}

We plan to recruit 240 middle-aged (40-65 years), cognitively normal adults with a $\mathrm{FH}+$ who are currently participating in moderate to vigorous intensity exercise fewer than 3 days/week for $30 \mathrm{~min}$ or more. Unlike ongoing PA trials with older adults ( $>65$ years), this study is uniquely positioned to address key gaps in knowledge by focusing on cognitively normal middle-aged adults with a heightened risk for $\mathrm{AD}(\mathrm{FH}+, A P O E 4+)$. These are people for whom benefits to cognitive performance and to underlying neurological and biological mechanisms may be more readily observed, and for whom effective interventions may ultimately delay cognitive decline. Therefore, we adopt an early therapeutic strategy that may offer the best opportunity for protective effects [101-104] by focusing on middle-aged adults. Importantly, the use of standardized measures allows us to discuss our results in the context of other studies, especially a similar clinical trial regarding the effects of physical activity on cognition and brain health in 65- to 80-year-old cognitively normal adults (Investigating Gains in Neurocognition in an Intervention Trial of Exercise, IGNITE trial; [105]).

\section{Eligibility criteria}

The goal of the eligibility criteria is to include middleaged English-speaking adults (40-65 years) with FH+ who are cognitively normal, who are not otherwise clinically impaired, who are healthy enough for exercise, and who are identified as sedentary according to American College of Sports Medicine (ACSM)'s guidelines [106]. Sedentary is defined as participating in physical activity at a moderate to vigorous intensity for $30 \mathrm{~min}$ or more, fewer than $3 \mathrm{x} /$ week over the last 3 months and is assessed by self-report.

The $\mathrm{FH}$ of dementia is defined as one first-degree or 2 second-degree relatives diagnosed with non-specific dementia or $\mathrm{AD}$. The relatively broad inclusion criteria with respect to FH reflect that 1$)$ the majority $(60-80 \%)$ of individuals diagnosed with non-specific dementia have $\mathrm{AD}$ and 2) volunteers at the lower end of the inclusion age range (e.g., 40-45 years) may have parents who are not sufficiently old to be likely to be diagnosed with AD. Individuals who only reported family members with diagnosed forms of dementia other than $\mathrm{AD}$, such as vascular dementia or dementia with Lewy bodies, are not included. Although APOE4+ make up approximately $24 \%$ of the general U.S. population $<65$ years of age [107], based upon previous research [37, 108], recruiting adults with a $\mathrm{FH}+$ increases the percent of $A P O E 4+$ to $\sim 35 \%$. Thus, by recruiting 240 people with a $\mathrm{FH}+$, we anticipate successfully enrolling approximately 80
APOE4+ participants. See Table 2 for an overview of inclusion and exclusion criteria.

\section{Recruitment strategies}

Participants are being recruited from six counties in North Carolina: rural (Randolph, Rockingham), regional city and suburban (Davidson, Alamance), and urban (Guilford, Forsyth). This recruitment strategy increases the diversity of our sample and contributes to the reproducibility of the results. The 6 counties have a combined population of approximately 469,588 in this age range [113]. We are advertising the study via local television, radio, billboards, car magnets, and newspapers; through emails, newsletters, and flyers distributed to support groups, places of worship, medical facilities, community centers, restaurants, and other locations; by giving community talks; and with social media posts. Given the demographics of the recruitment region, we aim to include approximately 125 women and 115 men.

\section{Informed consent}

Participants in this study are provided written informed consent at the first, in-person visit at the pre-test by research staff. More specifically, participants are explained all of the procedures, risks, potential benefits, and issues of confidentiality, provisions for collection and use of individual data and biological specimens, and provisions for care in the event of any adverse events. Participants are provided with enough time to make an informed decision, including time to ask any questions and discuss the study with the research staff. All participants in this study must go through a screening test to assess cognitive normality prior to being consented to participate in the study. Therefore, all participants are considered capable of ethically and medically consenting for participation on their own behalf.

\section{Procedures}

Eligibility for participation is initially assessed during a telephone interview. Individuals complete additional screening through online survey sets prior to their initial visit and complete the final assessments to determine eligibility at the pre-test. Eligible participants complete on-site pre-, mid-, and post-intervention assessments. After the pre-test, participants are randomly assigned to a 12-month PA intervention or a usual-care condition. See Table 3 for an overview of our protocol time schedule at five timepoints; screening (T0), pre-test (T1), allocation (T1.5), mid-test (T2), and post-test (T3).

\section{Telephone interview}

Research staff describe the study purpose, procedures, and requirements. Individuals who remain interested answer questions relative to the inclusion criteria and 
Table 2 Inclusion and exclusion criteria

\begin{tabular}{|c|c|c|}
\hline Inclusion criteria & Instrumentation & Cutoff \\
\hline 40-65 years of age & Telephone interview & \\
\hline Family history of dementia & $\begin{array}{l}\text { Telephone interview, Risk Evaluation } \\
\text { and Education for Alzheimer's disease } \\
\text { (REVEAL) questionnaire }\end{array}$ & $\begin{array}{l}1 \text { first degree relative or } 2 \text { second degree relatives } \\
\text { diagnosed with dementia or } A D \text { [109] }\end{array}$ \\
\hline Ability to communicate in English & Telephone interview & \\
\hline Not meeting PA guidelines & $\begin{array}{l}\text { American College of Sports Medicine } \\
\text { (ACSM)'s guidelines }\end{array}$ & $\begin{array}{l}30 \text { min of moderate intensity PA fewer than } \\
3 x / \text { week for the last } 3 \text { months [106] }\end{array}$ \\
\hline Exclusion criteria & Instrumentation & Cutoff \\
\hline Potential cognitive impairment & $\begin{array}{l}\text { Modified Telephone Interview for } \\
\text { Cognitive Status (TICS-m) }\end{array}$ & Total score < 33 [110] \\
\hline Potential cognitive impairment & $\begin{array}{l}\text { Montreal Cognitive Assessment } \\
\text { (MoCA) }\end{array}$ & Total score < 26 [111] \\
\hline $\begin{array}{l}\text { Current use of medications to treat symptoms } \\
\text { of } A D \text { or that adversely affect cognition }\end{array}$ & Self-report to a survey & \\
\hline $\begin{array}{l}\text { Cannot attend PA because of cardiovascular, } \\
\text { metabolic, or renal disease, or orthopedic limitations }\end{array}$ & $\begin{array}{l}\text { Medical Health History }(\mathrm{MHH}) \\
\text { physician clearance }\end{array}$ & \\
\hline $\begin{array}{l}\text { History of neurologic, psychiatric, or active } \\
\text { functionally disabling disease, or any other conditions } \\
\text { that might limit exercise or jeopardize participants }\end{array}$ & MHH questionnaire & \\
\hline Depression & $\begin{array}{l}\text { Center for Epidemiological Studies } \\
\text { Depression Scale - Revised (CESD-R) }\end{array}$ & $\begin{array}{l}\text { Total score }>16 \text { and having anhedonia or dysphoria } \\
\text { nearly every day for the past } 2 \text { weeks, and } 2 \text { or more } \\
\text { additional symptoms either nearly every day for the } \\
\text { past } 2 \text { weeks or } 5-7 \text { days in the past week or } \\
\text { indication for suicidal ideation [112] }\end{array}$ \\
\hline Uncorrected hearing or visual impairments & Self-report to a survey & \\
\hline $\begin{array}{l}\text { Plan for traveling for an extended period (more } \\
\text { than } 1 \text { month) during the course of the study }\end{array}$ & Self-report to a survey & \\
\hline
\end{tabular}

complete the Modified Telephone Interview for Cognitive Status (TICS-m) to ascertain initial eligibility for the study. The TICS-m has acceptable sensitivity and specificity in the detection of dementia [114] and amnestic MCI [110] and does not have the same ceiling constraints as other measures of cognitive impairment [110, 115]. Individuals are excluded if they score below the cutoff point of 33, which was determined to prioritize specificity over sensitivity [110]. These participants are contacted by the gerontological nurse practitioner (TMW) who explains the reason for their exclusion, answers questions, and advises them to contact their personal physician. Eligible participants are then sent the survey sets electronically.

\section{Survey sets}

After the telephone interview, eligible participants are further contacted by email (occasionally by telephone or postal mailing) to complete the following surveys: MRI safety screening questionnaire, Medical Health History (MHH) and medications list, Risk Evaluation and Education for AD (REVEAL, [109]) to evaluate family history of AD, Everyday Cognition Questionnaire [116] to measure perceived cognitive symptoms, Center for Epidemiological
Studies Depression Scale - Revised (CESD-R, [112]), Community Healthy Activities Model Program for Seniors [117] and International Physical Activity Questionnaire (IPAQ, [118]) to measure current PA behavior, Pittsburgh Sleep Quality Index [119], a perceived age questionnaire, and demographics. Prior to completing these surveys, informed consent is obtained for these data collection instruments. At this stage, participants who are excluded due to scores on the CESD-R are contacted by the gerontological nurse practitioner (TMW) who explains the reason for their exclusion, answers questions, and advises them to contact their personal physician.

\section{Pre-, mid-, and post-intervention assessment}

Most participants are tested over two visits at pre- and post-tests and one visit at mid-test. On the first visit of the pre-test, participants first read and sign an informed consent and complete the Montreal Cognitive Assessment (MoCA) for the final screening of cognitive normality. Individuals scoring below the cutoff point of 26 from the MoCA are excluded. The use of this cutoff results in excellent sensitivity in identifying MCI (90\%) and AD (100\%) and good specificity (87\%) [111]. Participants excluded based upon this criterion are referred to the gerontological 
Table 3 An overview of the study time schedule for assessments and interventions

\begin{tabular}{|c|c|c|c|c|c|}
\hline Timepoint & T0 & T1 & T1.5 & $\mathrm{T} 2$ & T3 \\
\hline \multicolumn{6}{|l|}{ Screening: } \\
\hline - Modified Telephone Interview for Cognitive Status (TICS-m) & $x$ & & & & \\
\hline - MRI safety screening & $x$ & & & & \\
\hline - Medical Health History (MHH) & $x$ & & & & \\
\hline - Questions from ACSM guidelines for determining risk of physical activity & $x$ & & & & \\
\hline - Alzheimer's family history questionnaire (REVEAL) & $x$ & & & & \\
\hline - Center for Epidemiological Studies Depression Scale Revised (CESD-R) & $x$ & & & & \\
\hline - Everyday Cognition Questionnaire (ECOG) & $x$ & & & & \\
\hline - Community Healthy Activities Model Program for Seniors (CHAMPS) & $x$ & & & & \\
\hline - Pittsburgh Sleep Quality Index & $x$ & & & & \\
\hline \multicolumn{6}{|l|}{ Enrollment } \\
\hline - Montreal Cognitive Assessment (MoCA) & & $x$ & & & \\
\hline - Informed consent & & $x$ & & & \\
\hline Allocation & & & $x$ & & \\
\hline \multicolumn{6}{|l|}{ Interventions: } \\
\hline - Physical activity & & & $\leftarrow$ — & 一一 & \\
\hline - Usual care & & & $\leftarrow$ - & - - & \\
\hline \multicolumn{6}{|l|}{ Assessments: } \\
\hline - Cognitive tests & & $x$ & & $x$ & $x$ \\
\hline - Neuroimaging & & $x$ & & & $x$ \\
\hline - Blood sample collection & & $x$ & & & $x$ \\
\hline - Resting heart rate assessment & & $x$ & & $x$ & $x$ \\
\hline - Submaximal exercise test & & $x$ & & $x$ & $x$ \\
\hline
\end{tabular}

nurse practitioner (TMW) and advised to discuss their cognitive performance with their physician.

After completing the MoCA, enrolled participants provide a saliva sample for $A P O E$ genotyping, have resting heart rate (HR) assessed, provide a fasted blood sample, are offered a light meal, perform cognitive tests, and complete a submaximal exercise test. The first visit takes about $5-5.5 \mathrm{~h}$. On the second visit of the pre-test, participants complete an MRI scan, which takes about $1.5 \mathrm{~h}$. Participants unwilling or unable to perform the MRI scan do not attend the second visit. For participants who need to come on 3 days, cognitive testing is divided into set $A$ and set B (see Table S1 in additional file 2 for more information) across two visits to accommodate their scheduling needs. For the estimation of aerobic fitness, participants complete a submaximal exercise test following the Modified Naughton protocol [106], however the first stage ( $1.0 \mathrm{mph}, 0 \%$ grade) is omitted. Changes in aerobic fitness provide an indicant of the physiological responsiveness to the PA intervention. At the mid- and post-tests, participants complete the same protocol except that blood sampling and MRI are only taken at the posttest and the saliva sample is not taken again.

\section{Interventions}

After completing the pre-test, participants are randomly assigned to conditions using a computerized randomization procedure implemented in R 3.6.1 [120]. To the extent possible, groups are matched on county of residence, age (4052/53-65), race (Caucasian/non-Caucasian), and gender (female/not female). Participants are informed of their group assignment by the project coordinator. Project staff conducting the testing are blinded to group assignment throughout the study. Participants are instructed not to discuss group assignment with any research staff during testing sessions.

\section{Physical activity condition (PAC)}

The PAC was used in previous research in which improvements in memory were observed in association with the program [38]. The PAC was originally based on meta-analytic evidence [25] indicating that in RCTs the largest effects of PA on cognition in older adults were in programs that include both aerobic and strength training $(g=0.59)$. Hence, the PAC includes both modes of activity. Subjects are asked to attend 3x/week for 1 year and exercise takes place in a group setting. Each subject is 
encouraged to walk on their own at a moderate intensity (target $\mathrm{HR}=40-59 \%$ HR reserve) dependent on resting HR and age [106]. Resting HR is assessed by palpation at approximately 3-week intervals. $\mathrm{HR}$ and ratings of perceived exertion (RPE) during exercise are assessed mid-way into walking, and RPE is assessed mid-way into strength training. Initially, walking is $10 \mathrm{~min} /$ day; this increases gradually until participants are walking for $30 \mathrm{~min} /$ day. For strength training, elastic resistance bands and possibly dumbbells are used. Subjects begin with bands with the least resistance, completing one set of 6-15 repetitions for each of 10-15 exercises. As they can complete 15 repetitions for any given exercise in proper form, they are progressed to the next higher resistance band for that exercise. As necessary, we progress to using two bands simultaneously or to dumbbells to continue to appropriately challenge the participants. In the first weeks of the PAC, more time is needed to teach the participants the exercises and to identify appropriate resistance levels. However, by week 8 , strength training is completed in 30 min; this is maintained throughout the intervention. In the event that participants cannot attend group sessions for an extended period of time, they are encouraged to continue to exercise as per the PAC protocol.

This PA program is inexpensive, safe, and suitable for community adult programs and home-based exercise recommendations. The program was implemented at local YMCAs until the COVID-19 pandemic and then through Zoom sessions after spring 2020. Fidelity across groups is ensured by using qualified and experienced Fitness Specialists who are trained to implement the program using the PAAD-2 Exercise Program Manual. Fidelity to the program and consistency of implementation across groups are further ensured by regular (at least once / 3 weeks) visits to each group to observe, evaluate, and provide feedback on sessions. Measures of compliance and adherence are obtained at all exercise sessions; groups are compared monthly to ensure no substantive differences exist. If such differences occur, we determine their causes and make necessary changes.

\section{Usual-care control (UCC)}

We use a UCC in which we ask participants to maintain their normal health practices (e.g., diet, annual physicals) for 1 year. Because the inclusion criteria require that participants not be regularly active, we anticipate that these individuals will not show consistent increases in PA over the year. To reduce effects from experimenter attention, to minimize attrition, and to assess possible crosscontamination, we provide educational materials (covering health topics, but not PA) to UCC participants biweekly. Once per month, we assess their self-reported PA [121] and once every 3 months we contact them by phone to ask if they have had any life changes relevant to the study. To encourage retention, we provide UCC participants with a short-term YMCA membership after the post-test. When participants are offered an intervention after a UCC waiting period, cross-contamination is low (7.1\% of studies) and fewer participants drop out from a UCC than an exercise treatment ( $4.7 \%$ fewer) in trials up to 1 year [121].

\section{Genotype}

Saliva samples are collected using Oragene-500 kits. Genomic deoxyribonucleic acid (DNA) is extracted from saliva samples for single nucleotide polymorphism (SNP) analysis. The SNPs associated with the two amino acid residues (codons 112 and 158) are used to identify participants as APOE4+ or APOE4-. Remaining DNA material is stored indefinitely for future analyses. All staff interacting with participants remain blinded to participants' APOE4 carrier status.

\section{Cognitive assessment}

We assess cognitive changes based on performance from a custom-built cognitive test battery consisting of wellestablished cognitive tests. Our primary interest in building the test battery was to include cognitive measures that are sensitive to early-to-advanced stages of $\mathrm{AD}$, especially verbal and visual episodic memory, auditory and visuospatial information processing, visuospatial constructional praxis, attention, and EFs [39]. We organized measures for EFs based on a well-established model [122], which consists of core EFs (inhibitory control, working memory, and cognitive flexibility) and higherorder EFs (planning, reasoning, and problem solving). Specific cognitive tests assessing each domain of episodic memory, core EFs, and higher-order EFs are described in the following section and depicted in Fig. 1. Protocols for each cognitive test are provided in additional file 2 . The timeline and order of cognitive tests are described in Table S1 in additional file 2. Our tests are administered using paper/pencil, a desktop computer (Dell, OptiPlex GX110), and/or an iPad 12.0 (Apple Inc.).

\section{Episodic memory}

We obtain a comprehensive evaluation of verbal and visual episodic memory since memory measures (rate of learning, short-term and long-term memory, retention of information, and retroactive and proactive interference) have been found most sensitive to a PA intervention in previous work [38] and episodic memory - both verbal and visual formats - is most sensitive to early stages of $\mathrm{AD}$ $[39,82]$. Verbal episodic memory is measured using the Rey Auditory Verbal Learning Test (RAVLT, [123], Digits Span Forward Test [124], and Virginia Cognitive Aging Project (VCAP [125])'s versions of the Paired Associates test [126] and Logical Memory test [127]. Visual episodic 


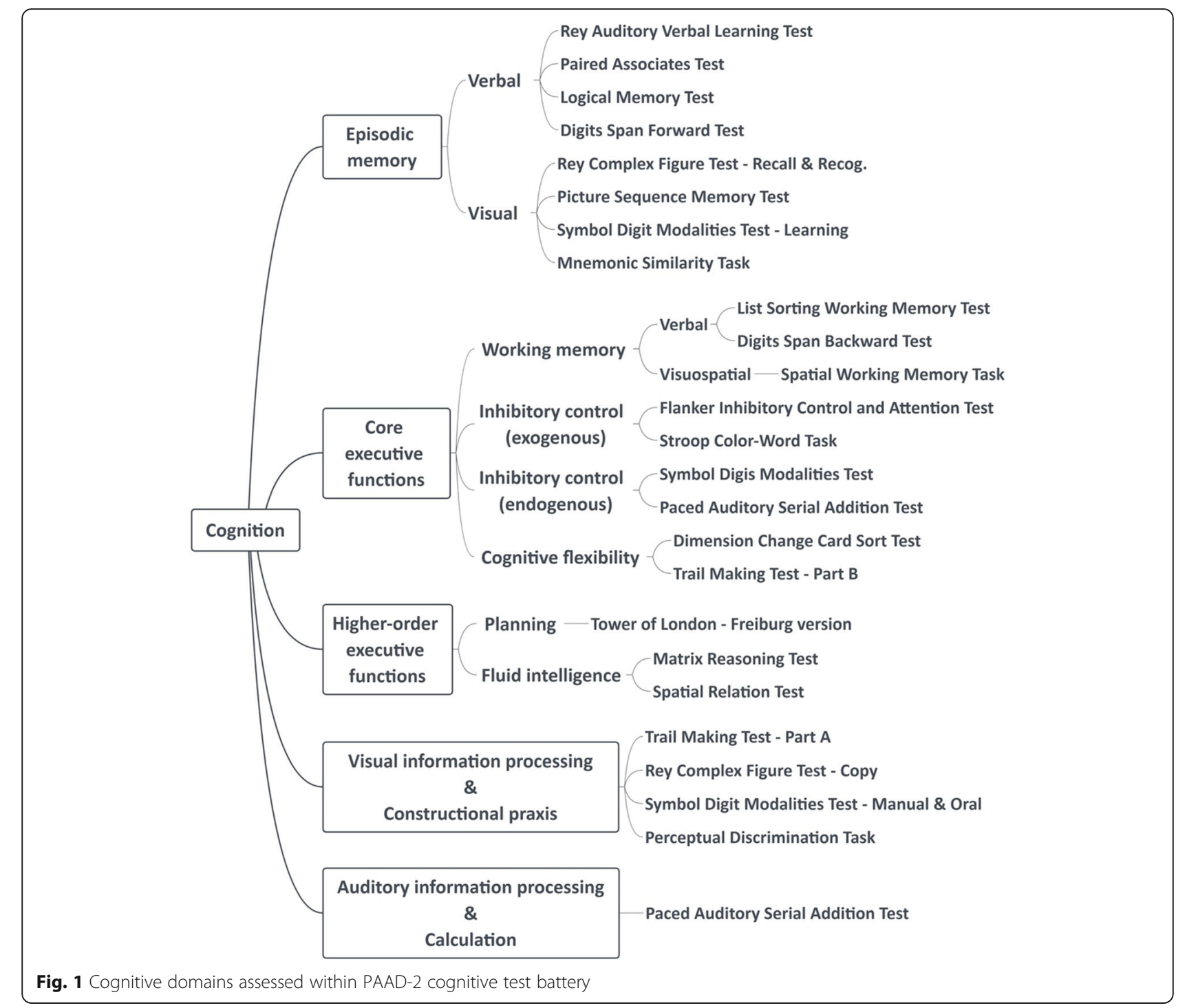

memory is measured using the Rey-Osterrieth Complex Figure Test [123, 128], the NIH Toolbox Picture Sequence Memory Test (PSMT [129]), and the Mnemonic Similarity Task (MST [130]). To prevent practice effects from repeated learning of the same stimuli [39], different forms in equivalent difficulties are used for the RAVLT [131, 132], Paired Associates, Logical Memory, PSMT, and MST for the pre-, mid-, and post-tests.

\section{Core executive functions}

Inhibitory control is defined as including both exogenous (stimulus-driven and involuntary) and endogenous (goaldriven and voluntary) attentional control [122]. Based on this definition, our testing battery includes the NIH Toolbox Flanker Inhibitory Control and Attention Test [133] and the Stroop Color-Word Task (the IGNITE version, [105]) to measure exogenous inhibitory control and the
Symbol Digit Modalities Test [134] and the Paced Auditory Serial Addition Test [135] to measure endogenous inhibitory control and selective attention.

Working memory is characterized by active attention, holding information in mind and mentally manipulating or updating it as necessary. This capability is critical for understanding and reacting to stimuli that change over time and requires mental maintenance of what happened earlier so that it can be linked to what comes later [122]. Distinguished by content, two major types of working memory are verbal and nonverbal (visual/spatial) working memory. Our test battery includes the NIH Toolbox List Sorting Working Memory Test [136] and the Digits Span Backward Test [124] to measure verbal working memory, and the IGNITE's spatial working memory task [21] to measure visuospatial working memory.

Cognitive flexibility, also known as set shifting, mental flexibility, or task switching, involves thinking creatively, 
seeing things from different perspectives spatially or interpersonally, and quickly and flexibly adapting to changed circumstances and demands [122]. We included the NIH Toolbox Dimensional Change Card Sort Test [133] and the Trail Making Test [137], which additionally assesses attention, visual processing speed, visual search, sequencing, and visuomotor skills.

\section{Higher-order executive functions}

Planning is defined as a "look-ahead mechanism designed to generate multiple sequences of hypothetical events and their consequences, including the development of stored structured event complexes that can guide movement from an initial to a goal state, execution-linked anticipation of future events, and recognition of goal attainment." [138], p. 655. Planning is assessed using the Tower of London - Freiburg version [139], a measure of planning with reliable and valid psychometric qualities [140, 141]. Fluid intelligence, also known as the reasoning and problem-solving subcomponents of EFs, represents the ability to do inductive and deductive logical reasoning, problem solving, and to figure out abstract patterns or relations among items [122]. We included the VCAP's versions of the Matrix Reasoning test [142] and the Spatial Relation test [143] to measure fluid intelligence.

\section{Blood biomarkers}

We use standard protocols for collection and storage of blood samples, assays, and analyses. Whole blood (approximately $45 \mathrm{ml}$ ) is collected in EDTA-treated and serum-separating tubes. Approximately $1 \mathrm{ml}$ of whole blood from the EDTA-treated tubes is extracted and mixed at a 1:1 ratio with Halt protease and phosphatase inhibitor (Thermo Fisher Scientific, USA) to protect from protein degradation, which is necessary to assay some of the biomarkers of interest (Table 1). The blood is then centrifuged, and serum, plasma, and Halt-treated plasma are stored in small aliquots at $-80^{\circ} \mathrm{C}$ to minimize freezethaw issues. Glucose and albumin are analyzed using commercially-available assay kits and requires $<70 \mu \mathrm{L}$ of serum to run both analytes in duplicate. All other assays are conducted using a multiplex system (Luminex 200S), which uses very small $(20-50 \mu \mathrm{L}$ total) volumes of blood. BDNF is given priority in any insufficient samples. Samples are stored indefinitely.

\section{MRI}

MRI exams are conducted at the Gateway MRI Center at pre- and post-test. Images are acquired on a Tim Trio Siemens $3 \mathrm{~T}$ MRI Scanner with a 12 channel receiveonly head coil. Sequences collected include a magnetization-prepared rapid acquisition with gradient echo (MPRAGE) T1-weighted structural scan, T2-
weighted-Fluid-Attenuated Inversion Recovery (T2FLAIR) scan, a resting-state echo planar imaging (EPI) scan, famous name discrimination task-evoked EPI scan, T2-weighted scan localized to the hippocampus and a diffusion-weighted scan. Associated images for distortion correction are acquired for EPI and diffusion images with a short spin echo EPI scan in the opposite phase encoding direction. Detailed information for each acquisition protocol is shown in Table 4.

All images are initially examined for quality control and movement artifact immediately following acquisition. The MRI data then get transferred to the server and undergo a rigorous quality control process. The data is converted from dicom to nifti format and the metadata is inspected for sequence accuracy and completeness. The data is then organized into brain imaging data structure (BIDS) format and visually inspected for brain coverage and orientation. Finally, quantitative quality control is completed for each sequence through the MRI Quality Control tool [144].

\section{Covariates}

Because cognitive performance is expected to be associated with age (e.g., [145-147]) and education (e.g., [146, 147]), these variables are included as covariates in the models. Identifying additional individual difference variables that discriminate levels of responsiveness to the intervention may provide important insights for subsequent research. Data on variables that have been identified as important in past research [11, 148-150] are collected and explored as potential covariates. These include sex, blood pressure, smoking, alcohol use, medications and supplements, sleep quality, body mass index, menopausal status, hormone therapy use, diabetes, and cardiovascular risk factors. When assessing $\mathrm{FH}$, detailed information regarding blood-related relatives suspected to have AD or diagnosed with AD is collected. This includes relationship to participant and age at diagnosis. We also collect data on parents who have not been diagnosed with AD (age and health status currently or at time of death). Because a $\mathrm{FH}+$ that is maternal and with a younger age of onset [151] results in higher risk, these variables are included as covariates in statistical analyses. Participants also complete the IPAQ [118] at pre, mid, and post-tests and monthly during the intervention.

\section{Data analysis}

The conceptual model driving our research is inherently a model of change: changes in PA lead to changes in cognitive performance. The current state of the art in statistical models for studying change is latent growth curve (LGC) analysis [152-154] which models trajectories of observed change as reflecting an underlying ("latent") developmental process. LGC analysis is an ideal 
Table 4 Magnetic Resonance Imaging Sequences

\begin{tabular}{ll}
\hline Sequence & Parameters \\
\hline T1-weighted MP-RAGE & Resolution $=1.0 \times 1.0 \times 1.0 \mathrm{~mm}, \mathrm{TR}=2300 \mathrm{~ms}, \mathrm{TE}=2.26 \mathrm{~ms}$, \\
& $\mathrm{Tl}=900 \mathrm{~ms}, \mathrm{FoV}=256 \mathrm{~mm}, 192$ slices \\
T2-FLAIR & Resolution $=1.0 \times 1.0 \times 1.0 \mathrm{~mm}, \mathrm{TR}=5000 \mathrm{~ms}, \mathrm{TE}=381 \mathrm{~ms}$, \\
& $\mathrm{Tl}=1800 \mathrm{~ms}, \mathrm{FoV}=256 \mathrm{~mm}, 192 \mathrm{slices}$
\end{tabular}

MP-RAGE Magnetization Prepared-RApid Gradient Echo, TR repetition time, TE echo time, TI inversion time, FoV Field of View, FLAIR Fluid-Attenuated Inversion Recovery, fMRI functional Magnetic Resonance Imaging

statistical tool for testing our conceptual model because it allows us to 1) estimate both mean and individual variation of pretest levels of our outcome variables (e.g., cognitive performance, neurological function/structure, and biomarkers), as well as means and variances of changes in those outcomes as a result of the intervention; 2) test whether PA and APOE4 status predict trajectories of changes in these outcomes; 3 ) determine whether changes in cognitive performance are mediated by putative mechanisms; and 4) test whether APOE4 status moderates the mediational associations.

\section{Power analysis}

We estimated sample size requirements using data from a previous study [38]. Coefficients on which we based our analysis included expected values for slope factors, regression estimates of association between predictors (PA, APOE4 status) and slope factors, and reasonable estimates of associations of the PA-by-APOE4 status interaction with slope factors. We conducted Monte Carlo simulations with 5000 replications, requiring estimate and variance bias of $<10 \%$, and coverage $\geq 95 \%$ [155], to estimate power for our target sample size of $N=240$ with attrition rates of $10-30 \%$. Time was coded such that parameter estimates represented expected mean monthly change over the course of the year-long intervention. An initial sample of 240 , provided the assumed attrition rates, would have an approximate power of 0.97 to detect a mean slope factor of 0.10 , power of $0.86-0.96$ to detect parameter estimates of $0.075-0.10$ for slope regressed on PA and APOE4 status, and power of $0.82-$ 0.92 to detect interaction effect estimates of $0.065-0.10$ for PA-by-APOE4 status regressed on slope.

\section{Data management}

Data include hardcopy surveys and data collection sheets, electronic surveys, and results of cognitive testing, MRI scans, genotype, and blood assays recorded electronically. All hard copies of data are linked to subject IDs without names and are stored in a locked cabinet in a laboratory. Electronic data are recorded by IDs and protected by password. A master list linking names to IDs is stored in a password protected file and separate from the data. Saliva and blood samples are stored in a locked laboratory. MRI data are stored on a password protected university server. When data are disseminated, it will not be in a way that would allow for the identification of any individual person. All data are managed using REDCap (Research Electronic Data Capture) hosted at the university [156]. REDCap is a secure, webbased software platform that allows us to control data access at the individual level and apply other rules and constraints that promote data quality.

Pre-test data from the first cohort will be examined to identify data gathering problems to be addressed immediately. The dataset will be cleaned using standard methods to identify impossible and improbable data [157] including frequency distribution checks for outliers and problems in data gathering or entry. Validity checks will be performed as recommended [157]. Standard Operating Procedures (SOPs) for cognitive testing, the PAC intervention, submaximal exercise testing, and blood draws are in place from our Phase I clinical trial (PAAD) [108]. Modifications to the SOP to reflect the addition of cognitive measures and updates to procedures were made prior to participant recruitment. MRI SOPs were developed based upon the existing MRI SOPs from the IGNITE trial [105] to maximize compatibility.

Two independent experts serve on the Data Safety and Monitoring Board to monitor participants' safety, the progress of the study, and the integrity of data collection. The principal investigator (JLE) makes safety and progress reports twice per year throughout the duration of the study. See additional file 3 (Data Safety Monitoring Plan) for more information. The data obtained in accordance with this protocol will be important to the relevant fields of science, 
and the PAAD-2 team has established a Data Sharing Plan regarding how, when, what, to whom the data will be disseminated. See additional file 4 for more information.

\section{Discussion}

In this protocol for a phase II randomized clinical trial, we describe the first experimental test of the effects of PA on cognitive performance in cognitively normal, middle-aged adults with a $\mathrm{FH}+$. In addition, we use sophisticated analytic techniques to assess moderated mediation models with $A P O E$ as a moderator and neurological and biological mechanisms as mediators across trajectories of cognitive change in response to the PA program. Our hypotheses are that 1 ) in individuals with a heightened risk for $A D$, PA will improve AD-related cognitive performance relative to controls; 2) the effects on cognitive performance will be moderated by APOE4 carrier status; and 3) changes in neural and blood biomarker will be observed in response to PA, will differ as a function of APOE4 carrier status, and will contribute to cognitive changes.

If persons with $\mathrm{FH}+$ who are in the PA program improve more than those in the control group, this will provide causal evidence of the viability of PA as a means of maintaining or improving cognitive performance in middle-age. If there are differential effects relative to APOE4 carrier status, this would indicate that PA is beneficial for cognition even in those with the greatest familial and genetic risk of AD. Our results are anticipated to elucidate the potential benefit of PA for persons with a $\mathrm{FH}+$ and the differential benefits relative to $A P O E 4$ status. This is a logical next step in advancing our understanding of the potential of PA as a therapeutic intervention for $\mathrm{AD}$. If $\mathrm{PA}$ is beneficial for individuals who are $\mathrm{FH}+$ and if PA is particularly advantageous for $A P O E 4+$, future work could then explore the potential of PA in middle-age to delay, or perhaps prevent, the onset of $\mathrm{AD}$ symptoms in persons with a heightened risk for $\mathrm{AD}$.

\section{Supplementary information}

Supplementary information accompanies this paper at https://doi.org/10. 1186/s12883-020-01732-1.

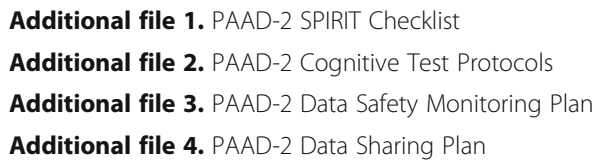

\section{Abbreviations}

ACSM: American College of Sports Medicine; AD: Alzheimer's disease; APOE4: Apolipoprotein epsilon 4 allele; APOE4-: Non-carriers of the apolipoprotein epsilon 4 allele; APOE4+: Carriers of the apolipoprotein epsilon 4 allele; BDNF: Brain-derived neurotrophic factor; BOLD: Blood oxygenation level-dependent; DNA: Deoxyribonucleic acid; EF: Executive function; EPI: Echo planar imaging; FH: Family history of Alzheimer's disease; FNDC5: Fibronectin type III domain containing 5; HR: Heart Rate; IGNITE: Investigating Gains in Neurocognition in an Intervention Trial of Exercise; LGC: Latent growth curve; MCI: Mild cognitive impairment; MoCA: Montreal Cognitive Assessment; MRI: Magnetic resonance imaging;
MST: Mnemonic Similarity Task; NIH: National Institutes of Health; PA: Physical activity; PAC: Physical activity condition; PAR-Q: Physical Activity Readiness Questionnaire for Everyone; PSMT: Picture Sequence Memory Test; RAVLT: Rey Auditory Verbal Learning Test; RCT: Randomized control trial; RPE: Ratings of perceived exertion; SAP: Serum amyloid P; SNP: Single nucleotide polymorphism; SOP: Standard Operating Procedures; TICSm: Modified Telephone Interview for Cognitive Status; UCC: Usual-care control; VCAP: Virginia Cognitive Aging Project

\section{Acknowledgements}

We thank Dr. Kirk Erickson at the University of Pittsburgh for his advice concerning the cognitive tests and sharing IGNITE's versions of the Stroop color-word task and spatial working memory test. We thank Dr. Timothy Salthouse at the University of Virginia for sharing the VCAP versions of the paired associates, logical memory, matrix reasoning, and spatial relation tests. We thank Dr. Christina Hugenschmidt at the Wake Forest School of Medicine for her contribution to the management and analysis of neuroimaging data.

\section{Authors' contributions}

JLE formulated the research question and wrote the detailed study protocol, along with significant contributions from KSP, ABG, NTB, YPM, WBK, JDL,

CNW, TMW, and LW to the conception and design of the study, data acquisition and analysis plans, and finalizing the study protocol. All authors read and approved the final manuscript and accept personal responsibility for the accuracy and integrity of the presentation of this protocol.

\section{Funding}

This study has been funded by the National Institute of Aging (NIA) of the National Institutes of Health (NIH) (award number: R01AG058919). A Scientific Review Group identified by the NIH provided a peer-review of the design of this study as part of grant award process. The reviewers' feedback was considered in the development of the final protocol. Other than that, the funding body has no role in the collection, analysis, and interpretation of data or in writing this manuscript or other manuscripts relevant to this research. The on-going role of the NIH is three-fold: to review annual progress reports, to determine if an interim analysis should be conducted; to decide if the study should continue or be stopped. The content of this manuscript is solely the responsibility of the authors and does not necessarily represent the official views of the $\mathrm{NIH}$.

\section{Availability of data and materials}

Data sharing is not applicable to this article as no datasets were generated or analyzed during the current study which describes an on-going study protocol. Pre-randomization data will be made available within 12 months of enrollment completion. Post-randomization data will be made available upon publication of the main findings of the study or 2 years following study closure (whichever comes first). After these dates, the datasets used and/or analyzed will be available from the corresponding author on reasonable request.

\section{Ethics approval and consent to participate}

Approval by the Institutional Review Board (IRB) of the University of North Carolina at Greensboro was obtained for the PAAD-2 (IRB number 18-0228). Subsequently, the IRB annually reviews the protocol and reviews modifications as necessary. Participants in this study provide consent prior to the completion of electronic surveys and are provide written informed consent at the first in-person visit at the pre-test. Participants in this study go through a screening test for cognitive normality before the first visit. Therefore, all participants are considered as being capable of ethically and medically consenting for participation on their own behalf. Individuals who do not meet the inclusion criteria for cognitive normality or for depression are encouraged to speak with their personal physician.

\section{Consent for publication}

Not applicable.

\section{Competing interests}

The authors declare no commercial, financial or any other conflict of interest in this research. 


\section{Author details}

'Department of Kinesiology, University of North Carolina at Greensboro, Greensboro, NC 27402, USA. ${ }^{2}$ Under Armour, Baltimore, MD 21209, USA. ${ }^{3}$ Department of Psychology, University of North Carolina at Greensboro, Greensboro, NC 27402, USA. ${ }^{4}$ Department of Advanced Nursing Practice and Education, East Carolina University, Greenville, NC 27858, USA.

\section{Received: 27 March 2020 Accepted: 16 April 2020}

\section{Published online: 06 June 2020}

\section{References}

1. Association As. 2019 Alzheimer's disease facts and figures. Alzheimers Dement. 2019;15(3):321-87.

2. International AsD. The world Alzheimer report 2019: attitudes to dementia. London: Alzheimer's Disease International; 2019.

3. Herrmann N, Chau SA, Kircanski I, Lanctot KL. Current and emerging drug treatment options for Alzheimer's disease: a systematic review. Drugs. 2011; 71(15):2031-65.

4. Kumar A, Singh A. Ekavali. A review on Alzheimer's disease pathophysiology and its management: an update. Pharmacol Rep. 2015;67(2):195-203.

5. Norton S, Matthews FE, Barnes DE, Yaffe K, Brayne C. Potential for primary prevention of Alzheimer's disease: an analysis of population-based data. Lancet Neurol. 2014;13(8):788-94.

6. Emery VO. Alzheimer disease: are we intervening too late? I neural Transm. 2011.

7. Brookmeyer R, Johnson E, Ziegler-Graham K, Arrighi HM. Forecasting the global burden of Alzheimer's disease. Alzheimers Dement. 2007;3(3):186-91.

8. Andel R, Crowe M, Pedersen NL, Fratiglioni L, Johansson B, Gatz M. Physical exercise at midlife and risk of dementia three decades later: a populationbased study of Swedish twins. J Gerontol A Biol Sci Med Sci. 2008;63(1):626.

9. Middleton LE, Barnes DE, Lui LY, Yaffe K. Physical activity over the life course and its association with cognitive performance and impairment in old age. J Am Geriatr Soc. 2010;58(7):1322-6.

10. Hamer M, Chida Y. Physical activity and risk of neurodegenerative disease: a systematic review of prospective evidence. Psychol Med. 2009;39(1):3-11.

11. Abbott RD, White LR, Ross GW, Masaki KH, Curb JD, Petrovitch H. Walking and dementia in physically capable elderly men. J Am Med Assoc. 2004; 292(12):1447-53.

12. Lindsay J, Laurin D, Verreault R, Hebert R, Helliwell B, Hill GB, et al. Risk factors for Alzheimer's disease: a prospective analysis from the Canadian study of health and aging. Am J Epidemiol. 2002;156(5):445-53.

13. Kim JM, Stewart R, Bae KY, Kim SW, Yang SJ, Park KH, et al. Role of BDNF val66met polymorphism on the association between physical activity and incident dementia. Neurobiol Aging. 2011;32(3):551 e5-12.

14. Beckett MW, Ardern Cl, Rotondi MA. A meta-analysis of prospective studies on the role of physical activity and the prevention of Alzheimer's disease in older adults. BMC Geriatr. 2015;15:9.

15. Sofi F, Valecchi D, Bacci D, Abbate R, Gensini GF, Casini A, et al. Physical activity and risk of cognitive decline: a meta-analysis of prospective studies. J Intern Med. 2011:269(1):107-17.

16. Daviglus ML, Plassman BL, Pirzada A, Bell CC, Bowen PE, Burke JR, et al. Risk factors and preventive interventions for Alzheimer disease: state of the science. Arch Neurol. 2011;68(9):1185-90.

17. Blondell SJ, Hammersley-Mather R, Veerman JL. Does physical activity prevent cognitive decline and dementia?: a systematic review and metaanalysis of longitudinal studies. BMC Public Health. 2014;14:510.

18. Fabre C, Chamari K, Mucci P, Masse-Biron J, Prefaut C. Improvement of cognitive function by mental and/or individualized aerobic training in healthy elderly subjects. Int J Sports Med. 2002;23(6):415-21.

19. Kramer AF, Hahn S, Cohen NJ, Banich MT, McAuley E, Harrison CR, et al. Ageing, fitness and neurocognitive function. Nature. 1999;400:418-9.

20. Dustman RE, Ruhling RO, Russell EM, Shearer DE, Bonekat HW, Shigeoka JW et al. Aerobic exercise training and improved neuropsychological function of older individuals. Neurobiol Aging. 1984;5(1):35-42.

21. Erickson KI, Voss MW, Prakash RS, Basak C, Szabo A, Chaddock L, et al. Exercise training increases size of hippocampus and improves memory. Proc Natl Acad Sci. 2011;108(7):3017-22.

22. Baker LD, Frank LL, Foster-Schubert K, Green PS, Wilkinson CW, McTiernan A, et al. Effects of aerobic exercise on mild cognitive impairment: a controlled trial. Arch Neurol. 2010;67(1):71-9.
23. Lautenschlager NT, Cox KL, Flicker L, Foster JK, van Bockxmeer FM, Xiao J, et al. Effect of physical activity on cognitive function in older adults at risk for Alzheimer disease: a randomized trial. JAMA. 2008;300(9):1027-37.

24. Angevaren M, Aufdemkampe G, Verhaar HJ, Aleman A, Vanhees L. Physical activity and enhanced fitness to improve cognitive function in older people without known cognitive impairment. Cochrane Database Syst Rev. 2008;(3):Cd005381.

25. Colcombe S, Kramer AF. Fitness effects on the cognitive function of older adults: a meta-analytic study. Psychol Sci. 2003;14(2):125-30.

26. Heyn P, Abreu BC, Ottenbacher KJ. The effects of exercise training on elderly persons with cognitive impairment and dementia: a meta-analysis. Arch Phys Med Rehabil. 2004;85(10):1694-704.

27. Hindin SB, Zelinski EM. Extended practice and aerobic exercise interventions benefit untrained cognitive outcomes in older adults: a meta-analysis. J Am Geriatr Soc. 2012;60(1):136-41.

28. Duara R, Barker WW, Lopez-Alberola R, Loewenstein DA, Grau LB, Gilchrist D, et al. Alzheimer's disease: interaction of apolipoprotein $E$ genotype, family history of dementia, gender, education, ethnicity, and age of onset. Neurology. 1996;46(6):1575-9.

29. Bendlin BB, Carlsson CM, Gleason CE, Johnson SC, Sodhi A, Gallagher CL, et al. Midlife predictors of Alzheimer's disease. Maturitas. 2010;65(2):131-7.

30. Scarabino D, Gambina G, Broggio E, Pelliccia F, Corbo RM. Influence of family history of dementia in the development and progression of lateonset Alzheimer's disease. Am J Med Genet B Neuropsychiatr Genet. 2016; $171 \mathrm{~B}(2): 250-6$

31. Rovio S, Kareholt I, Helkala EL, Viitanen M, Winblad B, Tuomilehto J, et al. Leisure-time physical activity at midlife and the risk of dementia and Alzheimer's disease. Lancet Neurol. 2005;4(11):705-11.

32. Schuit AJ, Feskens EJ, Launer LJ, Kromhout D. Physical activity and cognitive decline, the role of the apolipoprotein e4 allele. Med Sci Sports Exerc. 2001; 33(5):772-7.

33. Niti M, Yap KB, Kua EH, Tan CH, Ng TP. Physical, social and productive leisure activities, cognitive decline and interaction with APOE-epsilon 4 genotype in Chinese older adults. Int Psychogeriatr. 2008;20(2):237-51.

34. Deeny SP, Poeppel D, Zimmerman JB, Roth SM, Brandauer J, Witkowski S, et al. Exercise, APOE, and working memory: MEG and behavioral evidence for benefit of exercise in epsilon4 carriers. Biol Psychol. 2008;78(2):179-87.

35. Podewils LJ, Guallar E, Kuller LH, Fried LP, Lopez OL, Carlson M, et al. Physical activity, APOE genotype, and dementia risk: findings from the cardiovascular health cognition study. Am J Epidemiol. 2005;161(7):639-51.

36. Rodriguez FS, Schroeter ML, Arelin K, Witte AV, Baber R, Burkhardt R, et al. APOE e4-genotype and lifestyle interaction on cognitive performance: results of the LIFE-adult-study. Health Psychol. 2018;37(2):194-205.

37. Etnier JL, Caselli RJ, Reiman EM, Alexander GE, Sibley BA, Tessier D, et al. Cognitive performance in older women relative to ApoE-epsilon4 genotype and aerobic fitness. Med Sci Sports Exerc. 2007;39(1):199-207.

38. Etnier JL, Karper WB, Labban JD, Piepmeier AT, Shih CH, Dudley WN, et al. The physical activity and Alzheimer's disease (PAAD) study: cognitive outcomes. Ann Behav Med. 2018:52(2):175-85.

39. Lezak MD, Howieson DB, Loring DW, Hannay HJ, Fischer JS. Neuropsychological assessment, 4th ed. New York, NY, US: Oxford University Press; 2004. xiv, 1016-xiv, p.

40. Nagamatsu LS, Chan A, Davis JC, Beattie BL, Graf P, Voss MW, et al. Physical activity improves verbal and spatial memory in older adults with probable mild cognitive impairment: a 6-month randomized controlled trial. J Aging Res. 2013;2013:861893.

41. ten Brinke LF, Bolandzadeh N, Nagamatsu LS, Hsu CL, Davis JC, Miran-Khan $\mathrm{K}$, et al. Aerobic exercise increases hippocampal volume in older women with probable mild cognitive impairment: a 6-month randomised controlled trial. Br J Sports Med. 2015;49(4):248.

42. Marosi K, Mattson MP. BDNF mediates adaptive brain and body responses to energetic challenges. Trends Endocrinol Metab. 2014;25(2):89-98

43. Egan MF, Kojima M, Callicott JH, Goldberg TE, Kolachana BS, Bertolino A, et al. The BDNF val66met polymorphism affects activity-dependent secretion of BDNF and human memory and hippocampal function. Cell. 2003;112(2):257-69.

44. Egan MF, Weinberger DR, Lu B. Schizophrenia, III: brain-derived neurotropic factor and genetic risk. Am J Psychiatry. 2003;160(7):1242.

45. Hariri AR, Goldberg TE, Mattay VS, Kolachana BS, Callicott JH, Egan MF, et al. Brain-derived neurotrophic factor val66met polymorphism affects human memory-related hippocampal activity and predicts memory performance. J Neurosci. 2003;23(17):6690-4. 
46. Laske C, Stellos K, Hoffmann N, Stransky E, Straten G, Eschweiler GW, et al. Higher BDNF serum levels predict slower cognitive decline in Alzheimer's disease patients. Int J Neuropsychopharmacol. 2011;14(3):399-404.

47. Knaepen K, Goekint M, Heyman EM, Meeusen R. Neuroplasticity - exerciseinduced response of peripheral brain-derived neurotrophic factor: a systematic review of experimental studies in human subjects. Sports Med. 2010;40(9):765-801.

48. Seifert T, Brassard P, Wissenberg M, Rasmussen P, Nordby P, Stallknecht B, et al. Endurance training enhances BDNF release from the human brain. Am J Physiol Regul Integr Comp Physiol. 2010;298(2):R372-7.

49. Chao MV, Rajagopal R, Lee FS. Neurotrophin signalling in health and disease. Clin Sci (Lond). 2006;110(2):167-73.

50. Leckie RL, Oberlin LE, Voss MW, Prakash RS, Szabo-Reed A, ChaddockHeyman L, et al. BDNF mediates improvements in executive function following a 1-year exercise intervention. Front Hum Neurosci. 2014;8:985.

51. Vaughan S, Wallis M, Polit D, Steele M, Shum D, Morris N. The effects of multimodal exercise on cognitive and physical functioning and brainderived neurotrophic factor in older women: a randomised controlled trial. Age Ageing. 2014;43(5):623-9.

52. Fiala M, Veerhuis R. Biomarkers of inflammation and amyloid-beta phagocytosis in patients at risk of Alzheimer disease. Exp Gerontol. 2010; 45(1):57-63.

53. Kiddle SJ, Sattlecker M, Proitsi P, Simmons A, Westman E, Bazenet C, et al. Candidate blood proteome markers of Alzheimer's disease onset and progression: a systematic review and replication study. J Alzheimers Dis. 2014;38(3):515-31.

54. Prajapati KD, Sharma SS, Roy N. Current perspectives on potential role of albumin in neuroprotection. Rev Neurosci. 2011;22(3):355-63.

55. Akhtar MW, Sanz-Blasco S, Dolatabadi N, Parker J, Chon K, Lee MS, et al. Elevated glucose and oligomeric beta-amyloid disrupt synapses via a common pathway of aberrant protein S-nitrosylation. Nat Commun. 2016;7: 10242.

56. Ho N, Sommers MS, Lucki I. Effects of diabetes on hippocampal neurogenesis: links to cognition and depression. Neurosci Biobehav Rev. 2013;37(8):1346-62.

57. Anderson JR, Calvo D, Glickman E, Gunstad J, Spitznagel MB. The moderating role of insulin-like growth factor 1 in the relationship between cognitive and aerobic endurance change. J Geriatr Psychiatry Neurol. 2017 30(2):84-9.

58. Ding Q, Vaynman S, Akhavan M, Ying Z, Gomez-Pinilla F. Insulin-like growth factor I interfaces with brain-derived neurotrophic factor-mediated synaptic plasticity to modulate aspects of exercise-induced cognitive function. Neuroscience. 2006;140(3):823-33.

59. Maass A, Duzel S, Brigadski T, Goerke M, Becke A, Sobieray U, et al. Relationships of peripheral IGF-1, VEGF and BDNF levels to exercise-related changes in memory, hippocampal perfusion and volumes in older adults. Neurolmage. 2016;131:142-54.

60. Yamazaki Y, Painter MM, Bu G, Kanekiyo T. Apolipoprotein E as a therapeutic target in Alzheimer's disease: a review of basic research and clinical evidence. CNS drugs. 2016;30(9):773-89.

61. Hye A, Lynham S, Thambisetty M, Causevic M, Campbell J, Byers HL, et al. Proteome-based plasma biomarkers for Alzheimer's disease. Brain. 2006; 129(Pt 11):3042-50.

62. Bott NT, Bettcher BM, Yokoyama JS, Frazier DT, Wynn M, Karydas A, et al. Youthful processing speed in older adults: genetic, biological, and behavioral predictors of cognitive processing speed trajectories in aging Front Aging Neurosci. 2017;9:55.

63. Umegaki H, Makino T, Uemura K, Shimada H, Hayashi T, Cheng XW, et al. The associations among insulin resistance, hyperglycemia, physical performance, diabetes mellitus, and cognitive function in relatively healthy older adults with subtle cognitive dysfunction. Front Aging Neurosci. 2017;9:72.

64. Hofmann T, Elbelt U, Stengel A. Irisin as a muscle-derived hormone stimulating thermogenesis - a critical update. Peptides. 2014:54:89-100.

65. Wrann CD, White JP, Salogiannnis J, Laznik-Bogoslavski D, Wu J, Ma D, et al. Exercise induces hippocampal BDNF through a PGC-1alpha/FNDC5 pathway. Cell Metab. 2013;18(5):649-59.

66. Giunta S. Exploring the complex relations between inflammation and aging (inflamm-aging): anti-inflamm-aging remodelling of inflamm- aging, from robustness to frailty. Inflamm Res. 2008;57(12):558-63.

67. Pedersen BK. Exercise-induced myokines and their role in chronic diseases. Brain Behav Immun. 2011;25(5):811-6.
68. Packer N, Pervaiz N, Hoffman-Goetz L. Does exercise protect from cognitive decline by altering brain cytokine and apoptotic protein levels? A systematic review of the literature. Exerc Immunol Rev. 2010;16:138-62.

69. Windham BG, Wilkening SR, Lirette ST, Kullo IJ, Turner ST, Griswold ME, et al. Associations between inflammation and physical function in African Americans and European Americans with prevalent cardiovascular risk factors. J Am Geriatr Soc. 2016;64(7):1448-55.

70. Bugg JM, Head D. Exercise moderates age-related atrophy of the medial temporal lobe. Neurobiol Aging. 2011;32(3):506-14.

71. Erickson Kl, Prakash RS, Voss MW, Chaddock L, Hu L, Morris KS, et al. Aerobic fitness is associated with hippocampal volume in elderly humans. Hippocampus. 2009;19(10):1030-9.

72. Szabo AN, McAuley E, Erickson Kl, Voss M, Prakash RS, Mailey EL, et al. Cardiorespiratory fitness, hippocampal volume, and frequency of forgetting in older adults. Neuropsychology. 2011;25(5):545-53.

73. Colcombe SJ, Erickson Kl, Raz N, Webb AG, Cohen NJ, McAuley E, et al. Aerobic fitness reduces brain tissue loss in aging humans. J Gerontol A Biol Sci Med Sci. 2003;58(2):176-80.

74. Erickson Kl, Raji CA, Lopez OL, Becker JT, Rosano C, Newman AB, et al. Physical activity predicts gray matter volume in late adulthood: the cardiovascular health study. Neurology. 2010;75(16):1415-22.

75. Voss MW, Erickson Kl, Prakash RS, Chaddock L, Malkowski E, Alves H, et al. Functional connectivity: a source of variance in the association between cardiorespiratory fitness and cognition? Neuropsychologia. 2010;48(5):1394-406.

76. Colcombe SJ, Erickson KI, Scalf PE, Kim JS, Prakash R, McAuley E, et al. Aerobic exercise training increases brain volume in aging humans. $J$ Gerontol A Biol Sci Med Sci. 2006;61(11):1166-70.

77. Chapman SB, Aslan S, Spence JS, Defina LF, Keebler MW, Didehbani N, et al. Shorter term aerobic exercise improves brain, cognition, and cardiovascular fitness in aging. Front Aging Neurosci. 2013;5:75.

78. Colcombe SJ, Kramer AF, Erickson KI, Scalf P, McAuley E, Cohen NJ, et al. Cardiovascular fitness, cortical plasticity, and aging. Proc Natl Acad Sci U S A. 2004;101(9):3316-21.

79. Voss MW, Heo S, Prakash RS, Erickson Kl, Alves H, Chaddock L, et al. The influence of aerobic fitness on cerebral white matter integrity and cognitive function in older adults: results of a one-year exercise intervention. Hum Brain Mapp. 2013;34(11):2972-85.

80. Burdette JH, Laurienti PJ, Espeland MA, Morgan A, Telesford Q, Vechlekar $C D$, et al. Using network science to evaluate exercise-associated brain changes in older adults. Front Aging Neurosci. 2010;2:23.

81. Voss MW, Prakash RS, Erickson Kl, Basak C, Chaddock L, Kim JS, et al. Plasticity of brain networks in a randomized intervention trial of exercise training in older adults. Front Aging Neurosci. 2010;2.

82. Lind J, Larsson A, Persson J, Ingvar M, Nilsson LG, Backman L, et al. Reduced hippocampal volume in non-demented carriers of the apolipoprotein $E$ epsilon4: relation to chronological age and recognition memory. Neurosci Lett. 2006;396(1):23-7.

83. Tohgi H, Takahashi S, Kato E, Homma A, Niina R, Sasaki K, et al. Reduced size of right hippocampus in 39- to 80-year-old normal subjects carrying the apolipoprotein E epsilon4 allele. Neurosci Lett. 1997;236(1):21-4.

84. Burggren AC, Zeineh MM, Ekstrom AD, Braskie MN, Thompson PM, Small GW, et al. Reduced cortical thickness in hippocampal subregions among cognitively normal apolipoprotein E e4 carriers. Neuroimage. 2008:41(4):1177-83.

85. Fennema-Notestine C, Panizzon MS, Thompson WR, Chen CH, Eyler LT, Fischl B, et al. Presence of ApoE epsilon4 allele associated with thinner frontal cortex in middle age. J Alzheimers Dis. 2011;26(Suppl 3):49-60.

86. Wishart HA, Saykin AJ, McAllister TW, Rabin LA, McDonald BC, Flashman LA, et al. Regional brain atrophy in cognitively intact adults with a single APOE epsilon4 allele. Neurology. 2006;67(7):1221-4.

87. Alexander GE, Bergfield KL, Chen K, Reiman EM, Hanson KD, Lin L, et al. Gray matter network associated with risk for Alzheimer's disease in young to middle-aged adults. Neurobiol Aging. 2012;33(12):2723-32.

88. Nierenberg J, Pomara N, Hoptman MJ, Sidtis JJ, Ardekani BA, Lim KO. Abnormal white matter integrity in healthy apolipoprotein E epsilon4 carriers. Neuroreport. 2005;16(12):1369-72.

89. Persson J, Lind J, Larsson A, Ingvar M, Cruts M, Van Broeckhoven C, et al. Altered brain white matter integrity in healthy carriers of the APOE epsilon4 allele: a risk for AD? Neurology. 2006;66(7):1029-33.

90. Heise V, Filippini N, Ebmeier KP, Mackay CE. The APOE varepsilon4 allele modulates brain white matter integrity in healthy adults. Mol Psychiatry. 2011;16(9):908-16. 
91. Adluru N, Destiche DJ, Lu SY, Doran ST, Birdsill AC, Melah KE, et al. White matter microstructure in late middle-age: effects of apolipoprotein E4 and parental family history of Alzheimer's disease. Neuroimage Clin. 2014;4:730-42.

92. Bendlin BB, Ries ML, Canu E, Sodhi A, Lazar M, Alexander AL, et al. White matter is altered with parental family history of Alzheimer's disease. Alzheimers Dement. 2010;6(5):394-403.

93. Filippini N, MacIntosh BJ, Hough MG, Goodwin GM, Frisoni GB, Smith SM, et al. Distinct patterns of brain activity in young carriers of the APOEepsilon4 allele. Proc Natl Acad Sci U S A. 2009;106(17):7209-14.

94. Westlye ET, Lundervold A, Rootwelt H, Lundervold AJ, Westlye LT. Increased hippocampal default mode synchronization during rest in middle-aged and elderly APOE epsilon4 carriers: relationships with memory performance. J Neurosci. 2011;31(21):7775-83.

95. Sheline YI, Morris JC, Snyder AZ, Price JL, Yan Z, D'Angelo G, et al. APOE4 allele disrupts resting state $\mathrm{FMRI}$ connectivity in the absence of amyloid plaques or decreased CSF Abeta42. J Neurosci. 2010;30(50):17035-40.

96. Smith JC, Nielson KA, Woodard JL, Seidenberg M, Durgerian S, Antuono P, et al. Interactive effects of physical activity and APOE-epsilon4 on BOLD semantic memory activation in healthy elders. Neuroimage. 2011;54(1):635-44.

97. Best JR, Rosano C, Aizenstein HJ, Tian Q, Boudreau RM, Ayonayon HN, et al. Long-term changes in time spent walking and subsequent cognitive and structural brain changes in older adults. Neurobiol Aging. 2017;57:153-61.

98. Chang M, Jonsson PV, Snaedal J, Bjornsson S, Saczynski JS, Aspelund T, et al. The effect of midlife physical activity on cognitive function among older adults: AGES--Reykjavik study. J Gerontol A Biol Sci Med Sci. 2010;65(12):1369-74.

99. Friedland RP, Fritsch T, Smyth KA, Koss E, Lerner AJ, Chen $\mathrm{CH}$, et al. Patients with Alzheimer's disease have reduced activities in midlife compared with healthy control-group members. Proc Natl Acad Sci U S A. 2001;98(6):3440-5.

100. Chan AW, Tetzlaff JM, Altman DG, Dickersin K, Moher D. SPIRIT 2013: new guidance for content of clinical trial protocols. Lancet. 2013;381(9861):91-2.

101. Gehres SW, Rocha A, Leuzy A, Loss CM, Viola GG, Zimmer ER. Cognitive intervention as an early non-pharmacological strategy in Alzheimer's disease: a translational perspective. Front Aging Neurosci. 2016;8:280.

102. Liu-Seifert H, Andersen SW, Lipkovich I, Holdridge KC, Siemers E. A nove approach to delayed-start analyses for demonstrating disease-modifying effects in Alzheimer's disease. PLoS One. 2015;10(3):e0119632.

103. Blazer DG, Yaffe K, Karlawish J. Cognitive aging: a report from the Institute of Medicine. JAMA. 2015;313(21):2121-2.

104. Maliszewska-Cyna E, Lynch M, Oore JJ, Nagy PM, Aubert I. The benefits of exercise and metabolic interventions for the prevention and early treatment of Alzheimer's disease. Curr Alzheimer Res. 2017;14(1):47-60.

105. Erickson Kl, Grove GA, Burns JM, Hillman CH, Kramer AF, McAuley E, et al. Investigating Gains in Neurocognition in an Intervention Trial of Exercise (IGNITE): Protocol. Contemporary clinical trials. 2019;85:105832.

106. American College of Sports Medicine. ACSM's Guidelines for Exercise Testing and Prescription. 10th ed. Riebe D, editor. Philadelphia: Lippincott Williams and Wilkins; 2017

107. Raber J, Huang Y, Ashford JW. ApoE genotype accounts for the vast majority of AD risk and AD pathology. Neurobiol Aging. 2004;25(5):641-50.

108. Etnier JL, Labban JD, Karper WB, Wideman L, Piepmeier AT, Shih CH, et al. Innovative research design exploring the effects of physical activity and genetics on cognitive performance in community-based older adults. J Aging Phys Act. 2015;23(4):559-68.

109. Roberts JS, Cupples LA, Relkin NR, Whitehouse PJ, Green RC. Genetic Risk Assessment for Adult Children of People With Alzheimer's Disease: The Risk Evaluation and Education for Alzheimer's Disease (REVEAL) Study. Journal of Geriatric Psychiatry and Neurology. 2005;18(4):250-5.

110. Cook SE, Marsiske M, McCoy KJ. The use of the Modified Telephone Interview for Cognitive Status (TICS-M) in the detection of amnestic mild cognitive impairment. J Geriatr Psychiatry Neurol. 2009;22(2):103-9.

111. Nasreddine ZS, Phillips NA, Bedirian V, Charbonneau S, Whitehead V, Collin I, et al. The Montreal Cognitive Assessment, MoCA: a brief screening tool for mild cognitive impairment. J Am Geriatr Soc. 2005; 53(4):695-9.

112. Eaton WW, Smith C, Ybarra M, Muntaner C, Tien A. Center for Epidemiologic Studies Depression Scale: review and revision (CESD and CESD-R). In: Maruish ME, editor. The use of psychological testing for treatment planning and outcomes assessment. Volume 3: instruments for adults. 3rd ed. Mahwah: Lawrence Erlbaum Associates Publishers; 2004. p. 363-77.

113. United States Census Bureau. American community survey. Washington: United States Department of Commerce; 2010. http://factfinder2.census.gov/.
114. Manly JJ, Schupf N, Stern Y, Brickman AM, Tang MX, Mayeux R. Telephonebased identification of mild cognitive impairment and dementia in a multicultural cohort. Arch Neurol. 2011;68(5):607-14.

115. de Jager CA, Budge MM, Clarke R. Utility of TICS-M for the assessment of cognitive function in older adults. Int J Geriatr Psychiatry. 2003;18(4):318-24.

116. Farias ST, Mungas D, Reed BR, Cahn-Weiner D, Jagust W, Baynes K, et al. The measurement of everyday cognition (ECog): scale development and psychometric properties. Neuropsychology. 2008;22(4):531-44.

117. Stewart AL, Mills KM, King AC, Haskell WL, Gillis D, Ritter PL. CHAMPS physical activity questionnaire for older adults: outcomes for interventions. Med Sci Sports Exerc. 2001;33(7):1126-41.

118. Craig CL, Marshall AL, Sjostrom M, Bauman AE, Booth ML, Ainsworth BE, et al. International physical activity questionnaire: 12-country reliability and validity. Med Sci Sports Exerc. 2003;35(8):1381-95.

119. Buysse DJ, Reynolds CF, Monk TH, Berman SR, Kupfer DJ. The Pittsburgh sleep quality index: A new instrument for psychiatric practice and research. Psychiatry Research. 1989;28(2):193-213.

120. R Core Team. R: a language and environment for statistical computing. Vienna: R Foundation for Statistical Computing; 2019. https://www.R-project.org/.

121. Steins Bisschop CN, Courneya KS, Velthuis MJ, Monninkhof EM, Jones LW, Friedenreich $\mathrm{C}$, et al. Control group design, contamination and drop-out in exercise oncology trials: a systematic review. PLoS One. 2015;10(3):e0120996.

122. Diamond A. Executive functions. Annu Rev Psychol. 2013;64:135-68.

123. Rey A. L'examen clinique en psychologie. Paris: Presses universitaires de France; 1964.

124. Stern RA, White T. Neuropsychological assessment battery (NAB) digits forward/digits backward test professional manual. Lutz: Psychological Assessment Resources; 2003.

125. Salthouse TA. Contributions of the individual differences approach to cognitive aging. J Gerontol B Psychol Sci Soc Sci. 2017;72(1):7-15.

126. Salthouse TA, Fristoe N, Rhee SH. How localized are age-related effects on neuropsychological measures? Neuropsychology. 1996;10(2):272-85.

127. Wechsler D. Wechsler memory scale. 3rd ed. San Antonio: The Psychological Corporation; 1997.

128. Osterrieth PA. Le test de copie d'une figure complexe; contribution à l'étude de la perception et de la mémoire. [Test of copying a complex figure; contribution to the study of perception and memory]. Archives de Psychologie. 1944;30:206-356.

129. Bauer PJ, Dikmen SS, Heaton RK, Mungas D, Slotkin J, Beaumont JL. III. NIH TOOLBOX cognition battery (CB): measuring episodic memory. Monogr Soc Res Child Dev. 2013;78(4):34-48.

130. Stark SM, Yassa MA, Lacy JW, Stark CE. A task to assess behavioral pattern separation (BPS) in humans: data from healthy aging and mild cognitive impairment. Neuropsychologia. 2013;51(12):2442-9.

131. Shapiro DM, Harrison DW. Alternate forms of the AVLT: a procedure and test of form equivalency. Arch Clin Neuropsychol. 1990;5(4):405-10.

132. Hawkins KA, Dean D, Pearlson GD. Alternative forms of the Rey auditory verbal learning test: a review. Behav Neurol. 2004;15(3-4):99-107.

133. Zelazo PD, Anderson JE, Richler J, Wallner-Allen K, Beaumont JL, Weintraub S. II. NIH Toolbox cognition battery (CB): measuring executive function and attention. Monogr Soc Res Child Dev. 2013;78(4):16-33.

134. Smith A. Symbol digit modalities test manual (W-129C). Torrance: Western Psychological Services; 2011

135. Gronwall DM. Paced auditory serial-addition task: a measure of recovery from concussion. Percept Mot Skills. 1977:44(2):367-73.

136. Tulsky DS, Carlozzi NE, Chevalier N, Espy KA, Beaumont JL, Mungas D. V. NIH TOOLBOX COGNITION BATTERY (CB): MEASURING WORKING MEMORY. Monogr Soc Res Child Dev. 2013;78(4):70-87.

137. Reynolds CR. Comprehensive Trail-making test Examiner's manual. Austin: PRO-ED, Inc.; 2002.

138. Carlin D, Bonerba J, Phipps M, Alexander G, Shapiro M, Grafman J. Planning impairments in frontal lobe dementia and frontal lobe lesion patients. Neuropsychologia. 2000;38(5):655-65.

139. Kaller CP, Unterrainer JM, Kaiser S, Weisbrod M. Aschenbrenner S. Schuhfried: Tower of London - Freiburg version; 2012.

140. Kaller CP, Unterrainer JM, Stahl C. Assessing planning ability with the tower of London task: psychometric properties of a structurally balanced problem set. Psychol Assess. 2011;24(1):46-53.

141. Kaller CP, Rahm B, Köstering L, Unterrainer JM. Reviewing the impact of problem structure on planning: a software tool for analyzing tower tasks. Behav Brain Res. 2011;216(1):1-8. 
142. Raven J. Advanced progressive matrices, set II. London: H. K. Lewis; 1962.

143. Bennett GK, Seashore HG, Wesman AG. Differential aptitude tests. San Antonio: Psychological Corporation; 1997.

144. Esteban O, Birman D, Schaer M, Koyejo OO, Poldrack RA, Gorgolewski KJ. MRIQC: advancing the automatic prediction of image quality in MRI from unseen sites. PLoS One. 2017;12(9):e0184661.

145. Boone KB, Lesser IM, Hill-Gutierrez E, Berman NG, D'elia LF. Rey-osterrieth complex figure performance in healthy, older adults: relationship to age, education, sex, and IQ. Clin Neuropsychol. 1993;7(1):22-8.

146. Fastenau PS, Denburg NL, Hufford BJ. Adult norms for the Rey-Osterrieth complex figure test and for supplemental recognition and matching trials from the extended complex figure test. Clin Neuropsychol. 1999;13(1):30-47.

147. Schmidt M. Rey auditory verbal learning test: a handbook. Los Angeles: Western Psychological Services; 2004.

148. Weuve J, Kang JH, Manson JE, Breteler MM, Ware JH, Grodstein F. Physical activity, including walking, and cognitive function in older women. JAMA. 2004;292(12):1454-61.

149. Lytle ME, Vander Bilt J, Pandav RS, Dodge HH, Ganguli M. Exercise level and cognitive decline: the MoVIES project. Alzheimer Dis Assoc Disord. 2004; 18(2):57-64.

150. Yaffe K, Barnes D, Nevitt M, Lui LY, Covinsky K. A prospective study of physical activity and cognitive decline in elderly women: women who walk. Arch Intern Med. 2001;161(14):1703-8.

151. Maye JE, Betensky RA, Gidicsin CM, Locascio J, Becker JA, Pepin L, et al Maternal dementia age at onset in relation to amyloid burden in nondemented elderly offspring. Neurobiol Aging. 2016;40:61-7.

152. Curran PJ, Muthen BO. The application of latent curve analysis to testing developmental theories in intervention research. Am J Community Psychol. 1999;27(4):567-95

153. Duncan TE, Duncan SC, Strycker LA. An introduction to latent variable growth curve modeling: concepts, issues, and applications (2nd ed.) Mahwah: Lawrence Erlbaum Associates Publishers; 2006.

154. Duncan TE, Duncan SE. An introduction to latent growth curve modeling. Behav Ther. 2004;35(2):333-63.

155. Muthen LK, Muthen BO. How to use a Monte Carlo study to decide on sample size and determine power. Struct Equ Model. 2002;9(4):599-620.

156. Harris PA, Taylor R, Thielke R, Payne J, Gonzalez N, Conde JG. Research electronic data capture (REDCap)--a metadata-driven methodology and workflow process for providing translational research informatics support. J Biomed Inform. 2009;42(2):377-81.

157. Davidson F. Principles of statistical data handling. New York: Sage; 1996.

\section{Publisher's Note}

Springer Nature remains neutral with regard to jurisdictional claims in published maps and institutional affiliations.

Ready to submit your research? Choose BMC and benefit from:

- fast, convenient online submission

- thorough peer review by experienced researchers in your field

- rapid publication on acceptance

- support for research data, including large and complex data types

- gold Open Access which fosters wider collaboration and increased citations

- maximum visibility for your research: over $100 \mathrm{M}$ website views per year

At $\mathrm{BMC}$, research is always in progress.

Learn more biomedcentral.com/submissions 